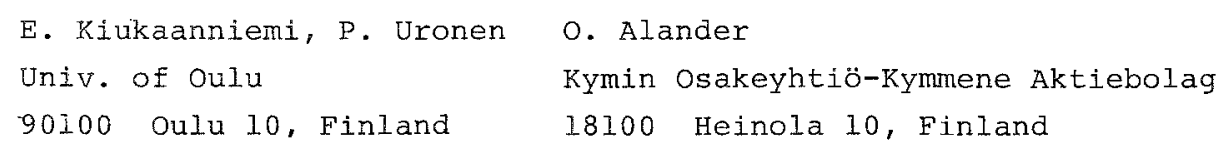

1. PREFACE

Recent development in energy prices has turned the attention of man to energy sources: new sources are searched for and conventional means of energy production are critically investigated in order to optimize their utilization.

One source of energy, the importance of which has been realized with the advance of increasing fuel prices, is peat, a renewing resource of nature typical for some areas in northern Europe. Because of the comparatively difficult processing properties of peat and the quite short history of efficient development on this area the technology of peat burning plants now needs a systematic programme of development, especially concerning small and middle-sized plants. The present work is aimed at identifying and mapping practical possibilities for optimizing the total economic performance of the plant type in question. The following principal programme was used:

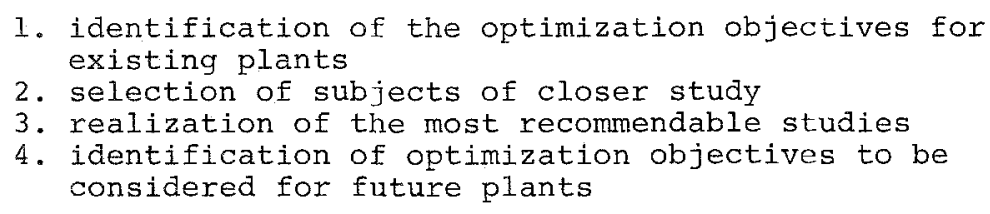

The present work necessarily will have a practical character due to the specific problem but simultaneously it shows the need for modelling and optimization studies when plant development procedures in generally are planned. The straightforward approach taken here partly reflects also a situation quite common for practical decision making: available data is limited and also non-numerical information has to be used. 
1. OPTIMIZATION OBJECTIVES FROM A COST SUDY AND OPERATING EXPERIENCES

In order to select optimally the subjects of studies aimed at improving the profitability of a plant, the cost structure of the plant has to be investigated. Combined with operating experience a cost study can give useful information, both for users of present plants and for designers of future plants.

Prior to attacking more specific details and overall weighting of optimization objectives will be a recommendable type of preliminary study, especially for a plant which is in the phase of development and has not yet reached its 'best', final construction. In small and middlesized peat burning plants this situation clearly will be valid. Thus when developing this type of plant we first have to define individual subjects of development work or a set of studies and then among them to pick up in order of priority those subjects, which will satisfy adequately the following general requirements:

$\mathrm{Rl}$ : realizable with existing resources

R2: economically profitable

R3: recommendable from the plant user's point of view

A cost study combined with operating experience will show if a proposed study satisfies requirements $R 2$ and $R 3$. Resources for carrying out studies and development work are very different for the designer and user of a plant. Thus especially in the case of plant user the value of obtainable development may be strongly limited. The requirement Rl can be naturally satisfied optimally by a well-organized co-operation between plant users, designers and financiers of development work.

\subsection{COST STUDY AND OPERATING EXPERIENCE}

In any producing plant the following types of cost can be separated:

1. capital costs

2. costs of energy needed in plant operation

3. maintenance costs

4. fuel costs

5. salaries

There are additionally some minor costs as taxes, insurances etc., which are not discussed here. In the test plant the above grouping of costs resulted in the distribution of procentual annual costs given in Table 1. The column 'chances of cost reduction' summarizes shortly recommendable subjects of study. The information about possibilities to reduce different costs actually forms a qualitative model for plant development, which in practice proceeds through individual decisions concerning subjects such as shown in Table 1 . 
TABLE 1. RELATIVE COSTS AND SOME CENTRAI TOPICS OF DEVELOPMENT

(relative costs from the test plant in-74)

\begin{tabular}{|c|c|c|}
\hline cost type & percentage & chances of cost reduction, $c_{j}, j=1, \ldots, 11$ \\
\hline $\begin{array}{l}\text { 1. capital } \\
\text { costs }\end{array}$ & 28. & $\begin{array}{l}\text { 1. lighter building and silo constructions } \\
\text { could be considered in future plants }\end{array}$ \\
\hline $\begin{array}{l}\text { 2. energy } \\
\text { costs }\end{array}$ & 8. & $\begin{array}{l}\text { 2. dryer feed i.e. less energy would be consu- } \\
\text { med in blowing water vapor in flue gases / / } \\
\text { 3. improvements of the design of flue gas ways } \\
\text { in cyclon and boiler } \\
\text { 4. improvements of the design of feeder systems } \\
\text { according to minimum energy consumption }\end{array}$ \\
\hline $\begin{array}{l}\text { 3. mainte- } \\
\text { nance }\end{array}$ & 7. & 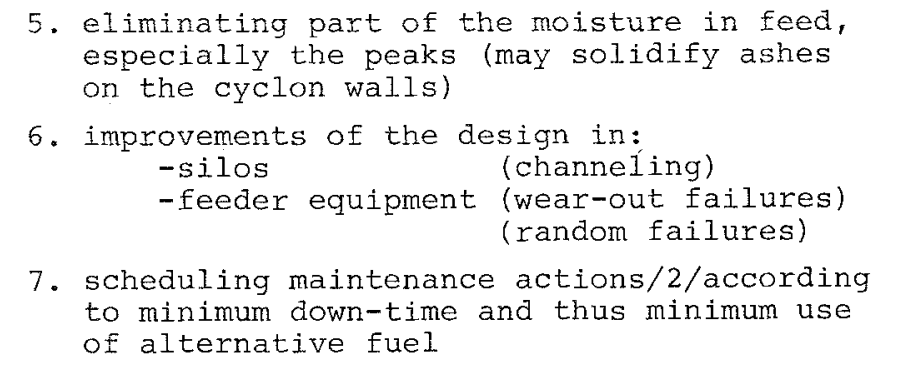 \\
\hline $\begin{array}{l}\text { 4. fuel } \\
\text { costs }\end{array}$ & 38. & $\begin{array}{l}\text { 8. efficiency improvements in heat production } \\
\text { lines, as an example improved waste heat } \\
\text { recovery by pre-drying peat with flue gases } \\
\text { 9. minimizing the use of alternative fuel } \\
\text { (used during down-times due to larger } \\
\text { failures and repairs, especially the down- } \\
\text { times due to the cycion should be avoided) }\end{array}$ \\
\hline 5. salaries & 18. & $\begin{array}{l}\text { 10. less supervision would be needed if obtain- } \\
\text { able improvements were carried out in: } \\
\text {-silos (channeling avoided) } \\
\text {-feeder eq. (wear-out, random failures) } \\
\text {-cyclon (extraction of ashes in } \\
\text {-ash handling (no manual operations) } \\
\text { 11. decreased need of supervision might reduce } \\
\text { costs paid as salaries. Thus also an effec- } \\
\text { tive system Ior the very supervising work } \\
\text { should be considered; depending on the size } \\
\text { of the plant it could consist of: } \\
\text {-a centralized control room } \\
\text { - rv-facilities and automation of a } \\
\text { suitable degree. } \\
\text { Computer supervising system might be econo- } \\
\text { mic enough in larger plants. }\end{array}$ \\
\hline & 100. & \\
\hline
\end{tabular}

The potential available for cost reductions in a peat burning plant can be studied by beginning with a similar table as above and analyzing it with an accuracy suitable for the purpose. A similar table with about 
the same elements in the rightmost column could be evidently formed also for other present small and middle-sized peat burning plants with different constructions.

\subsection{SELECTION OF SUBJECTS OF CLOSER STUDY}

The utilization of the information in Table 1 . demands selection of a few central subjects of closer study, because a simultaneous investigation of all subjects would need very large resources. In order to evaluate the quantitative weights of each chance $c_{j}$ the requirements (I) should be tested. Then for each $c_{j}, j=1, \ldots, 11$ here, a weight $j$ of the form (3) can be estimated.

$w_{j}=\sum_{i=1}^{3} k_{i} R_{i j}$, where

$i=$ current number of requirements (1)

$\mathrm{k}_{i}=$ coefficient of the mutual weighting of requirements (1)

$\mathrm{R}_{i j}^{1}=$ parameter expressing the degree according to which a given subject of study $c_{j}$ will satisfy requirements (1)

In practice we can expect that some additional subjects of study can be defined which will affect on several types of costs, for example predrying would do so. Thus the sum of type (4) would give the summed weight $w_{\text {mix }}$ for each of such 'mixed' subjects of study, which also may lead, when succeeded, to cost reducing improvements.

$$
\begin{aligned}
w_{\operatorname{mix}} & =\sum_{j=1} w_{j} \text { ' where } \\
j= & \text { current number of. } c_{j} \text { 's in Table } 1 \\
j_{\max }= & \begin{array}{l}
\text { total number of } c_{j} ' s, \text { the available chances of cost } \\
\text { reduction. }
\end{array}
\end{aligned}
$$

In this preliminary study we have not explicitly carried out the evaluation of Eqs. (3) and (4) but have represented the equations here to show that a quantitative discussion of $\mathrm{c}_{j}$ 's in Table 1 . would be possible if needed. In practice the selection of subjects of closer study was carried out very much according to the principle involved in above equations: those subjects were selected, which apparently are central in Table $1 .$, satisfy requirements ( 1 ) and the cost effects of which concern several types of costs:

1. failure behaviour of the plant

2. pre-drying of the peat

Additional support for the selection could obviously be obtained by applying Eqs. (3) and (4) to the selected tasks.

The identification of parameters needed in weighting Eqs. (3) and (4) clearly will be quite laborious but gives useful information for decision making. 


\section{FAILURE BEHAVIOUR OF THE PLANT}

The central type of failure in a peat burning plant appears to be deterministic i.e. the time of occurrence of a failure can be approximately predicted. Quite pure wear-out failures will occur in the feeder system (screw conveyors, feed blowers and flue gas blowers). Failures in the cyclon can be regarded as indirect wear-out failures (caused by frequent extraction of ashes); these failures clearly show a need for extracting ashes in fluidized phase. An additional deterministic type of failure has shown to be the shanneling of peat in silos. Also this failure shows a need for improvements in the design of silos or buffer store by demanding quite regular attention of the supervising personnel. This task of supervising in turn will cause indirectly a part of the costs paid as salaries.

\subsection{PRESENT VALUES OF PERIODIC FAILURES}

Assuming that mean time between failures for a component remains approximately constant or no improvements in the failing component are made, we can estimate the average annual cost due to a given failure and regard it as an annual payment or annuity. For an annuity we can obtain the corresponding present value $\mathrm{H}_{j}$ when the total time of annually paid costs is known /4/, as Eq. (5):

$H_{j}=a_{j} \times \frac{(1+i)^{n}-1}{i(1+i)^{n}}$, where

$\mathrm{H}_{j}=$ present value of a periodically paid cost due to

$a_{j}=$ an estimate of the average annual cost due to component $j$

$i=$ present rate of interest

$\mathrm{n}=$ total time of periodic costs.

A suitable estimate for the total time of periodically paid costs could be the expected useful life of the total plant equipment, taken usually as 10-20 years for heat producing equipments.

The total sum of the present values for the periodic failure costs in a plant actually represents the available economic potential for component improvements. Therefore it can be used as one evaluable measure when performances of peat burning plants with different constructions are compared. For the test plant this sum will be about half of the corresponding present value for expectable costs of maintenance to be paid in ten years time. This shows that a considerable potential for component improvements exists. 


\section{PRE-DRYING OF THE PEAT}

In the test plant the temperature of gases leaving the preheater of burning air varies, $140-190^{\circ} \mathrm{C}$, depending on the air excess and the moisture content of the peat. Because of the low sulphur content of peat, about $0.2 \mathrm{w}-\frac{\%}{\circ}$ the temperature of flue gases could be lowered without a significant risk of corrosion in the flue gas channels. Thus a more efficient recovery of the heat content of flue gases would be physically 'allowed'. This heat content would be efficiently utilized when used in pre-drying the peat, which improvement according to Table 1. , for example, would be very desirable. The main effects of pre-drying are schemed below.

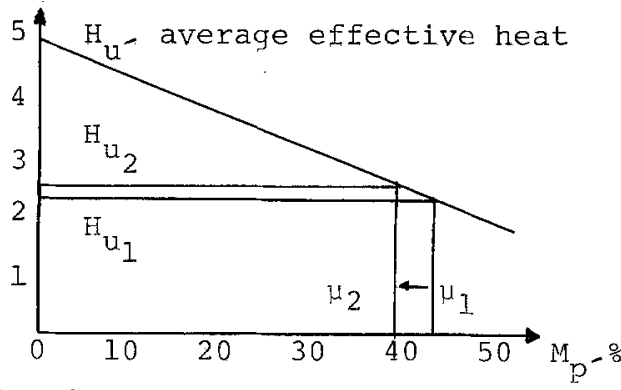

Fig. 1. Average effective heat $\mathrm{H}_{\mathrm{p}}$ vs moisture content of u the peat $M_{\mathrm{p}} / 1 /$

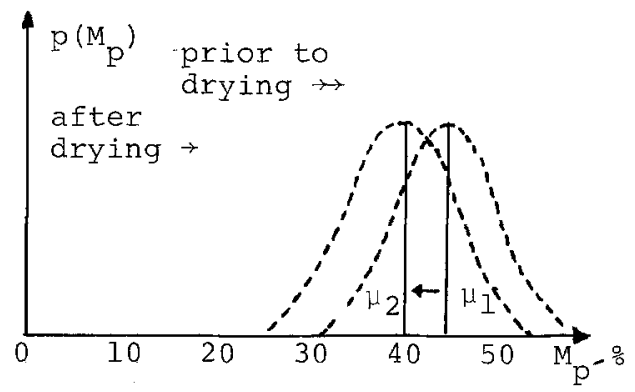

Fig. 2. Effect of pre-drying on the probability distri-

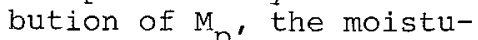
re content $\mathrm{g}_{f}$ the peat

The use of flue gases in pre-drying would naturally cause additional costs due to recirculation equipment and energy. Therefore these negative cost effects of the pre-drying should be weighted against the following positive effects:

1. improved utilization of the waste heat of flue gases; for example a drying result of $10 \%$ would mean a $5 \%$ reduction in fuel costs

2. direct costs of maintenance obviously decreased (cyclon repairs)

3. decreased need of supervision because of an imrpoved continuity of the combustion

4. better possibilities of extracting the ashes from the cyclon in fluidized phase continuously and automatically, because a temperature higher than in present cyclons could be maintained

5. possibly small reductions in the size of the boiler

6. the plant as a whole less sensitive for variations in fuel moisture and thus reductions in the need of supervision expectable.

Some preliminary experimental results of pre-drying have already been obtained at Kymin Osakeyhtiö, Heinola, and they are favourable for the continuation of the study. 


\section{A COST MODEL FOR SEEKING OPTIMAL PLANT COMPOSITIONS}

Plants using different fuels need different equipments for fuel storing, handling and combustion. This fact results in that also the corresponding distributions for the annual relative costs (2) will be different, which as such would be an interesting subject of study for different pairs of fuels because of the continuous development in fuel prices.

In this discussion, however, the differences in the cost structures of two plants using different fuels are interpreted as a potential for seeking optimal plant compositions for future two-fuel plants. Preliminary studies show that for plants of small capacity the two-fuel composition can be more profitable than the corresponding one-fuel alternatives, dependent on the annual demand characteristics and the ratio of unit prices of the two fuels.

\subsection{COST STRUCTURE FOR A TWO-FUEL PLANT}

Facilities for using alternative fuel in a heating plant may be needed for a couple of reasons:

- expectable changes in fuel prices

- uncertain availability and quality of the base fuel

- possible technical difficulties in maintaining continuous heat production using only the base fuel

The practical reasons will show a need for modelling the cost structure of a two-fuel plant, in order to compare it with the limiting one-fuel alternatives. Especially for peat-oil plants the above reasons seem to be relevant, because the technology of peat combustion units in plants of low capacity still allows development.

In a two-fuel plant part of the demand will be satisfied by the base fuel and the rest by the alternative fuel, called here aid fuel. The effective share of the designed aid fuel capacity will be decisive for the total economy of the two-fuel plant. Therefore we have selected it as the free variable in the following model of annual costs for a two-fuel plant. In the following discussion the total costs of a twofuel plant are formed as a sum of the main cost types. The effect of plant capacity will be implicitly taken into account through the relative magnitudes of the cost types involved in the cost function.

The presented cost model is primarily constructed for peat-oil plants and therefore the following discussion will concentrate on the features characteristic for this specific type of two-fuel plants. 
1. Fuel costs. The annual demand curve for a given heating plant usually shows that the plant must be flexibly adaptable to both short and long term variations of the demand, the minimum capacity needed being in practice about half of the maximal demand of capacity. A cycle of the annual long term variation is shown schematically in Fig. 4. assuming a smoothed (effective) representation for a typical annual demand curve.

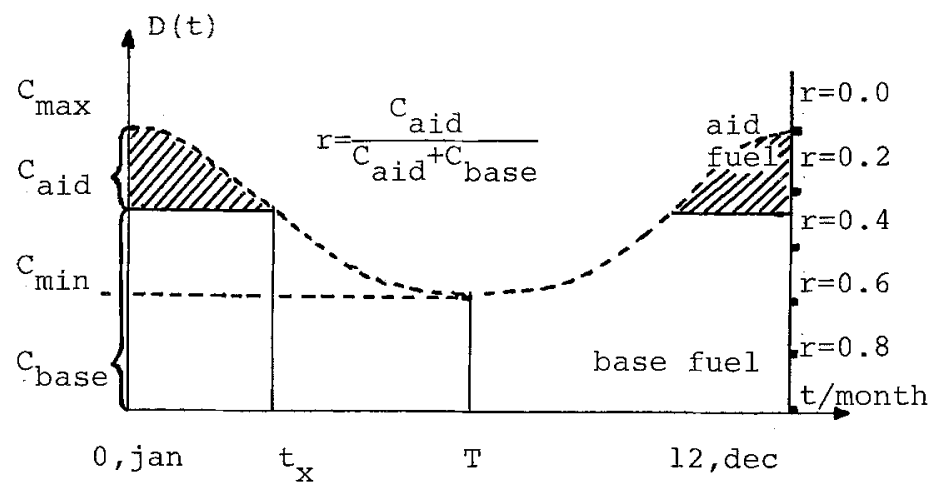

Fig. 4. Sharing of the heat production capacity between the base and aid fuels

Using the notations of the above figure we obtain for the fuel costs of a two-fuel plant:

$$
\begin{aligned}
& \frac{1}{2} C_{\text {fuel }}(r)=\frac{w_{\text {aid }}}{w_{\text {base }}} \int_{0}^{t_{x}}\left\{(t)-C_{\text {base }}\right\} d t+\int_{0}^{t_{x}} C_{\text {base }} d t \\
& \mathrm{~T} \\
& +\int_{t_{x}} D(t) d t \text {, where } \\
& w_{\text {base }}=\text { coefficient for the unit price of the base fuel } \\
& \mathrm{w}_{\text {aid }}=\text { coefficient for the unit price of the aid fuel } \\
& t_{X}(r)=\text { an aid variable to be estimated using the demand curve } \\
& \mathrm{T}=\text { time corresponding to the minimum demand } \mathrm{C}_{\text {min }}
\end{aligned}
$$

Depending on the shape of the demand curve and ratio of prices of the two fuels the total fuel costs (6) as a function of the increasing $r$ will be an increasing function (7) as shown in Fig. 5.

In real plants the shape of the long term demand curve can vary considerably depending on the type of load in the network. The two extremes are a constant demand and a demand which occurs seasonally. Between these two extremes is the present case of demand which is usual in small district heating plants. 


$$
\frac{d\left\{C_{\text {fuel }}(r)\right\}}{d r} \geq \operatorname{otr}[0.1 .0]
$$

As can be seen in Fig. 5., the cost effect of using more expensive aid fuel is smallest for lower values of the $r$.

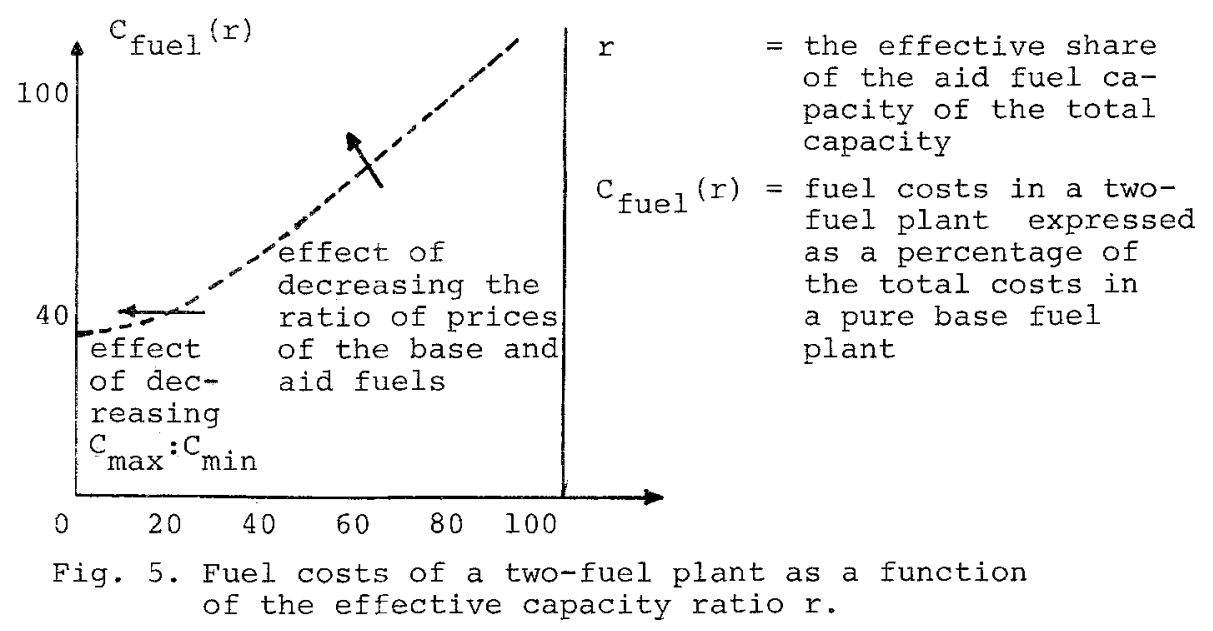

A similar principal study concerning the rest of the main costs as a function of the $r$ will be of interest especially for low values of the $r$.

2. Capital costs. The construction of the heating plant will be actually selected among three choices: one-fuel plant for the base fuel, a two-fuel plant for the base and aid fuels and a one-fuel plant for the aid fuel. Thus the capital costs will be in practice fixed by the selection of the plant composition.

In a heating plant there usually are at least two heat production units, preferably one separate units for the base load and for the more variable peak load. In a peat-oil plant one of the units, recommendably the unit for the peak demand, could be replaced by a cheaper oil unit. This change in plant composition would clearly offer means for reducing the initial plant investment so also the capital costs. Therefore the principal form of the capital cost curve as a function of the $r$ will be of decreasing type. Small discontinuities at both ends can be expected due to changes in plant composition. 3. Maintenance costs. The decreasing function will be evident also for the costs of maintenance, because the oil units clearly need less maintenance than the present peat combustion units. Thus when replacing 
a peat unit by an oil unit, considerable savings in maintenance costs can be expected.

4. Energy costs. Mainly because of the feeder system for the fuel and the system for blowing combustion air and flue gases a peat unit consumes more energy than a corresponding oil unit. Thus replacement of a peat unit by an oil unit will reduce cost of energy used in the plant. A decreasing function of energy costs as a function or the $r$ will result.

5. Salaries. Salaries of the supervising personnel is cost factor which reflects the ease of operating the plant. A peat unit needs, at least using present plant constructions, much more attention of the supervising personnel than an oil unit. Thus replacement of a peat unit by an oil unit clearly reduces the need of supervision and correspondingly also costs paid as salaries. Therefore also here a decreasing function of costs will result when the $r$ is increased.

The above principal discussion shows that, except for the fuel costs, all costs will show different types of decreasing tendencies as one or more peat units in a heating plant are replaced by oil units. Approximating the sum of capital, energy, maintenance and salary costs with a linear dependence as a function of the $r$, we obtain the following function for the total annual costs in a two-fuel plant:

where

$$
\begin{aligned}
J(r)= & k_{1}\left(c_{0}-k \cdot r\right)+2 k_{2}\left[\left\{\frac{w_{\text {aid }}}{w_{\text {base }}} \int_{0}^{t}\left\{D(t)-C_{\text {base }}\right\} d t\right.\right. \\
& \left.\left.t_{X} \int_{0} C_{\text {base }} d t+\int_{t_{X}}^{T} D(t) d t\right\}\right]
\end{aligned}
$$

$\mathrm{k}_{2,1}=$ coefficients for the relative shares of fuel costs and non-fuel costs respectively in a one-fuel plant using only base fuel

$\mathrm{c}_{\mathrm{O}}=$ relative share of non-fuel costs in a one-fuel plant using only base fuel

$k$ = decay factor for non-fuel costs, other notations same as in $\mathrm{Eq}$. (6) .

The total costs $J(r)$ must be solved numerically in order to study if a minimum for the total costs can be found for an $r \varepsilon(0,1.0)$. If an optimum can not be found, one of the limiting one-fuel plants will be optimal as to the total costs.

The continuous representation of non-fuel costs in Eq. (8) is not strictly correct, because the possible combinations of available peat and oil units will form a discrete set of alternatives. The linear 
function adopted thus represents the first approximation for a set of discrete points.

The relative shares of different cost types will be also a function of plant capacity. The fuel costs will be dominant in plants of large capacity and in small and middle-sized plants the share of other costs, capital, maintenance, energy costs and salaries, will be more significant. This effect is clearly of importance in selecting the most profitable plant compositions especially for plants of small capacity. The cost function of type (8) can be used to verify numerically cost effects represented schematically in Fig. 6 .

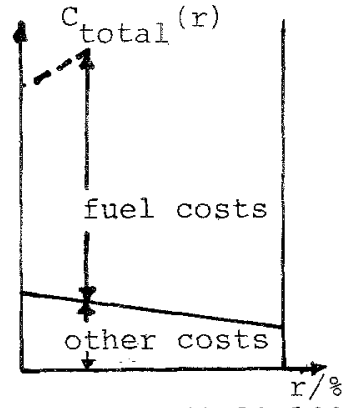

$0 \quad 20 \quad 40 \quad 60 \quad 80 \quad 100$

1. Large plants: fuel costs dominant

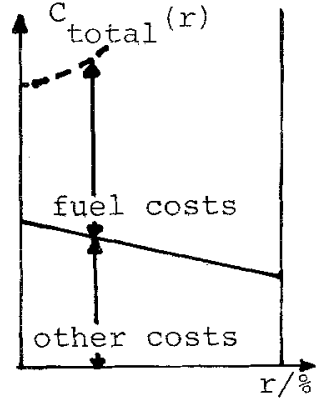

$02040 \quad 60 \quad 80 \quad 100$

2. medium plants; the share of fuel costs decreased

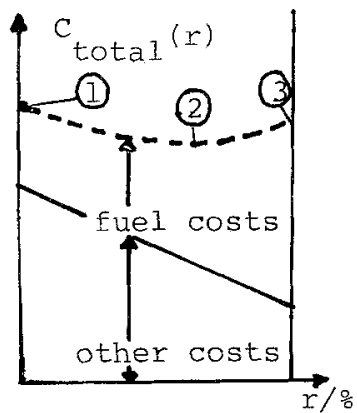

$0 \quad 20 \quad 40 \quad 60 \quad 80 \quad 100$

3. small plants; capital, maintenance energy costs and salaries dominant

Fig. 5. Effect of plant capacity on relative costs in a two-fuel plant

The estimation of the total cost curve as a function of the $r$ for $a$ given plant capacity requires estimation of the economic parameters and the demand curve involved in Eq. (8). The estimation of the parameters will presuppose knowledge of the actual plant construction alternatives and availability of real cost information, which sometimes is difficult to achieve. However, the cost model of Eq. (8) will offer a possibility to study the following important topics:

1. the existence of the optimum for total costs in small heating plants i.e. the locations of the points (1), (2) and (3) in Fig. 6. can be tested numerically and, consequently, the corresponding most profitable plant composition can be established

2. numerical simulation of the cost effects caused by changes in different economic parameters, for example fuel prices, can be carried out for two-fuel plants. 
The applicability of the model is clearly limited to two-fuel plants where unit prices of the two fuels differ considerably from each other and different heat production units are used for the base fuel and the aid fuel. In peat-oil plant the situation will be this provided that different boilers are used for peat and oil.

\section{SUMMARY}

A systematic approach for seeking and selecting optimization objectives for small and middle-sized peat burning plants has been proposed. The main possibilities available for plant optimization have been stated and discussed referring to the example plant. Partly qualitative and partly quantitative grounds for employing a new component, the pre-dryer of the peat, have been found and considered to be adequate for laboratory scale studies. Preliminary results appear to be favourable.

A model for seeking optimal plant compositions for a two-fuel plant has been introduced. The model allows numerical studies of the expectable profitability of different plant compositions for future peat-oil plants, thus accomplishing the previous discussion on plant optimization.

Future studies concerning peat burning plants will concentrate on studying mechanisms of enlargements for heating plants subject to given demand characteristics.

\section{LITERATURE CITED AND SUGGESTED READINGS:}

1. Enqvist, E., On the Combustion of Peat, Work of Diploma, TKK 1972, pp. 8-19.

2. Jardine, A.K.S., Operational Research in Maintenance, Manchester Univ. Press, 1970, pp. 20-43.

3. Hirvonen, E., Cost Calculations, Second Ed., Turku 1974, pp. 126-9.

4. Peters, M.S., Timmerhaus, K.D., Plant Design and Economics for Chemical Engineers, McGraw-Hill, Sec. Ed., 1968, pp. 242-3, 265-6.

5. Wells, G.L., Process Engineering with Economic Objective, Intertext 1973.

\section{ACKNOWLEDGEMENTS:}

This work was supported in part by the Ministry of Commerce and Industry and the Building Department of the Ministry of Defence.

Experiments needed were carried out by Kymin Osakeyhtiö-Kymmene. Aktiebolag, Heinola, Finland. 